\title{
ERNEST DRLANDI LAWRENCE BERKELEY NATIINAL LABIRATIRY Changing Ventilation Rates in U.S. Offices: Implications for Health, Work Performance, Energy, and Associated Economics
}

William J. Fisk, Douglas Black, and Gregory Brunner

Environmental Energy Technologies Division

July 2011 


\section{Disclaimer}

This document was prepared as an account of work sponsored by the United States Government. While this document is believed to contain correct information, neither the United States Government nor any agency thereof, nor The Regents of the University of California, nor any of their employees, makes any warranty, express or implied, or assumes any legal responsibility for the accuracy, completeness, or usefulness of any information, apparatus, product, or process disclosed, or represents that its use would not infringe privately owned rights. Reference herein to any specific commercial product, process, or service by its trade name, trademark, manufacturer, or otherwise, does not necessarily constitute or imply its endorsement, recommendation, or favoring by the United States Government or any agency thereof, or The Regents of the University of California. The views and opinions of authors expressed herein do not necessarily state or reflect those of the United States Government or any agency thereof, or The Regents of the University of California.

Ernest Orlando Lawrence Berkeley National Laboratory is an equal opportunity employer. 


\title{
Changing Ventilation Rates in U.S. Offices: Implications for Health, Work Performance, Energy, and Associated Economics
}

\author{
William J. Fisk, Douglas Black, and Gregory Brunner
}

July 2011

Environmental Energy Technologies Division

Indoor Environment Department

Lawrence Berkeley National Laboratory

Berkeley, CA 94720

This study was funded through interagency agreement DW-89-92224401 between the Indoor Environments Division, Office of Radiation and Indoor Air of the U.S. Environmental Protection Agency (EPA) and the U. S. Department of Energy under contract DE-AC02-05CH11231, to develop an IAQ Scientific Findings Resource Bank (see www.iaqscience.lbl.gov). Conclusions in this paper are those of the authors and not necessarily those of the U.S. EPA. 
Published in Building and Environment (2011) http://dx.doi.org/10.1016/j.buildenv.2011.07.001

Changing Ventilation Rates in U.S. Offices: Implications for Health, Work Performance, Energy, and Associated Economics

\author{
William J. Fisk ${ }^{\mathrm{a}}$, Douglas Black ${ }^{\mathrm{a}}$, Gregory Brunner ${ }^{\mathrm{b}}$ \\ ${ }^{a}$ Indoor Environment Department \\ 1 Cyclotron Rd, 90R3058 \\ Lawrence Berkeley National Laboratory \\ Berkeley, CA 94720 \\ ${ }^{\mathrm{b}}$ Indoor Environments Division \\ U.S. Environmental Protection Agency \\ 1200 Pennsylvania Ave NW, Mail Code 6609J \\ Washington, DC 20460 \\ ${ }^{*}$ Corresponding author: \\ William Fisk \\ wjfisk@lbl.gov \\ Tel. (510) 486-5910 \\ Fax: (510) 4866658
}




\section{ABSTRACT}

This paper provides quantitative estimates of benefits and costs of providing different amounts of outdoor air ventilation in U.S. offices. For four scenarios that modify ventilation rates, we estimated changes in sick building syndrome (SBS) symptoms, work performance, short-term absence, and building energy consumption. The estimated annual economic benefits were $\$ 13$ billion from increasing minimum ventilation rates (VRs) from 8 to $10 \mathrm{~L} / \mathrm{s}$ per person, \$38 billion from increasing minimum VRs from 8 to $15 \mathrm{~L} / \mathrm{s}$ per person, and \$33 billion from increasing VRs by adding outdoor air economizers for the $50 \%$ of the office floor area that currently lacks economizers. The estimated $\$ 0.04$ billion in annual energy-related benefits of decreasing minimum VRs from 8 to $6.5 \mathrm{~L} / \mathrm{s}$ per person are very small compared to the projected annual costs of $\$ 12$ billion. Benefits of increasing minimum VRs far exceeded energy costs while adding economizers yielded health, performance, and absence benefits with energy savings.

\section{KEYWORDS}

cost-benefit analysis, economizer, health, office, ventilation rate, work performance 


\subsection{INTRODUCTION}

How much outdoor air ventilation should be provided to buildings? Providing more ventilation increases building energy consumption, increases the related emissions of carbon dioxide, and contributes to climate change. Modeling of the U.S. commercial building stock [1] indicates that $6.5 \%$ of all end-use energy (3.2\% in offices) is for heating and cooling of mechanically-supplied outdoor air ventilation. Using the data in [1], one can estimate that an additional $3 \%$ of total end-use energy is used to heat and cool infiltration air, thus, an estimated $9.5 \%$ of end use energy is required for ventilation. From an energy and climatechange perspective, we want to reduce ventilation rates. However, providing less ventilation increases indoor concentrations of many indoor-generated air pollutants, although indoor concentrations of some outdoor air pollutants are decreased. In offices, for which the largest amount of data are available, higher VRs are associated with greater satisfaction with indoor air quality, fewer SBS symptoms, and improved work performance [2-4]. Limited research also indicates that higher VRs are associated with reduced absence rates in offices [5] and schools [6], possibly because providing more ventilation may reduce transmission of infectious respiratory illnesses [7].

Despite the long-standing debate about the correct values for minimum VRs, there have been few attempts to quantitatively compare the benefits and costs of ventilation. The minimum VRs specified in existing and most older standards for commercial buildings are based primarily on decades-old laboratory studies showing that $80 \%$ of unadapted occupants were satisfied with air quality with a VR of about $7.5 \mathrm{~L} / \mathrm{s}$ per person in a situation with people as the primary indoor pollutant source [8]. The current U.S. ventilation standard for offices [9] maintains approximately this same minimum ventilation rate if the building has a default (typical) occupant density but divides the minimum ventilation requirement into two components, one a minimum rate of outdoor air supply per occupant and the second a minimum rate of outdoor air supply per unit floor area. Today, we have more information to consider when setting standards, particularly for office buildings. Accordingly, this paper provides quantitative estimates of benefits and costs of providing different amounts of outdoor air ventilation in U.S. offices. The estimates should be of value for decisions about building operation and setting of minimum ventilation rate standards.

\subsection{METHODS}

Four scenarios were evaluated, each with changes in VRs in U.S. office buildings. The analysis is of hypothetical scenarios in which buildings actually have the specified minimum VRs. As a base case, we used a minimum VR of $8 \mathrm{~L} / \mathrm{s}$ per person - just slightly below the minimum rate of $8.5 \mathrm{~L} / \mathrm{s}$ per person for offices in the ASHRAE ventilation standard with the default occupant density of 5 persons per $100 \mathrm{~m}^{2}$ of floor area [9]. In scenario 1 , the minimum VR was increased to $10 \mathrm{~L} / \mathrm{s}$ per person -- a common minimum VR for offices in standards around the world and the minimum VR for offices in a prior version of the ASHRAE ventilation standard. In scenario 2, the minimum VR was increased to $15 \mathrm{~L} / \mathrm{s}$ per person which is still considered well within the capacity of most existing heating, ventilating, and air conditioning (HVAC) systems. In scenario 3, the minimum VR is decreased to $6.5 \mathrm{~L} / \mathrm{s}$ per person. In scenario 4, the minimum VR was retained at $8 \mathrm{~L} / \mathrm{s}$ per person and outdoor air economizers were added to the $50 \%$ of the existing U.S. office floor space that does not have economizers (http://www.eia.doe.gov/emeu/cbecs/ ,May 6, 2011). An economizer is a control system that increases the VR above a minimum value when this additional amount of ventilation will reduce the energy needed for air conditioning. Economizers can substantially increase annual-average VRs. We assumed that scenarios 1 through 3 do not affect VRs 
during periods of economizer activation. The impacts of the scenarios on prevalence rates of SBS symptoms, work performance, short-term absence, and building energy consumption, and the associated economic impacts, were estimated. In addition, for scenario 4 the cost of adding economizers was estimated.

For the relationship of VRs in offices with prevalence rates of SBS symptoms [4], the following equation was employed:

$$
R S P=\exp \left(0.00089 x^{2}-0.0542 x+0.453\right)
$$

where RSP is the relative SBS symptom prevalence, equal to the expected SBS symptom prevalence with a VR of $x$ (in L/s per person) divided by the expected SBS symptom prevalence if the building had a VR of $10 \mathrm{~L} / \mathrm{s}$ per person. This equation, based on a statistical analysis of published data from eight studies and 43 data points, indicates the average relationship for a range of SBS symptom types across a range of VRs from 5 to $35 \mathrm{~L} / \mathrm{s}$ per person.

For the relationship of VRs in offices with office work performance [3], the following equation was employed

$$
R W P_{V R}=\exp \left(\left(-76.38 x^{-1}-078 x \operatorname{Ln}(x)+3.87 x-y_{0}\right) / 1000\right)
$$

where $R W P_{V R}$ is the relative work performance as affected by VR, $x$ is the VR in L/s per person and $\mathrm{y}_{0}$ is calculated as follows

$$
y_{o}=-76.38 X_{R}^{-1}-0.78 X_{R} \operatorname{Ln}\left(X_{R}\right)+3.87 X_{R}
$$

where $X_{R}$ is a reference value of VR. Equation 2 applies for VRs of 6.5 to $47 \mathrm{~L} / \mathrm{s}$ per person. This equation is based on statistical analysis of research data from nine studies and 26 data points. Equations 1-3 are illustrated graphically at www.iaqscience.lbl.gov (May 6, 2011). It is important to note that the studies analyzed by Seppänen et al. [3] to derive equations 2 and 3 involved only call center work and work tasks for which speed and accuracy could be readily quantified. In actual practice, the effects of ventilation rate on work performance may vary substantially with type of work, with indoor pollutant sources, and with other factors that affect indoor air quality. In most of the studies analyzed by Seppänen et al. [3] the occupant density was high.

The findings of a study in 40 buildings [5] were employed to estimate the relationship of office VR with short-term absence. This study found that the adjusted relative risk (RR) for short-term absence at 24 versus $12 \mathrm{~L} / \mathrm{s}$ per person was 0.66 . We used an exponential model to predict the RR associated with other changes in VR

$$
R R=0.66^{(x / 12)}
$$

where $x$ is the change in VR in L/s per person. These estimates have higher uncertainty than those described above because of the reliance on the results of a single study; however, supportive findings are available from a study of VRs and absence in classrooms [6] and there is a body of evidence [7] indicating that lower VRs may increase respiratory infections, which are a major cause of absence. The calculations extrapolate with equation 4 to lower VRs than 
encountered in the original study. This extrapolation may cause an underestimation of the impacts of VR on absence because we expect the benefits of increased VR to be larger in buildings with initially low values of VR.

To estimate changes in numbers of workers experiencing SBS symptoms, values of RSP were multiplied by the estimated SBS symptom prevalence rate at the base case VR of $8 \mathrm{~L} / \mathrm{s}$ per person, and by the office worker population. We started with the average prevalence (16.8\%) of weekly eye, nasal, headache, and tiredness/fatigue symptoms [10] from a survey of 100 U.S office buildings, as these were the types of symptoms considered for derivation of equation 1. The geometric mean VR in the survey was $18.3 \mathrm{~L} / \mathrm{s}$ per person, thus SBS symptom prevalence will be higher in our base case with $8 \mathrm{~L} / \mathrm{s}$ per person. With equation 1 , an average SBS symptom prevalence of $23 \%$ was projected at $8 \mathrm{~L} / \mathrm{s}$ per person. Similarly, to calculate changes in days of short-term absence, we also required an estimate of the base case rate of short term absence at a VR of $8 \mathrm{~L} / \mathrm{s}$ per person. We conservatively used the reported short term absence rate of $2 \%$ at a VR of $12 \mathrm{~L} / \mathrm{s}$ per person [5] which translates to 4.8 days per year assuming 240 work days.

For the analyses of scenarios 1 through 3, the fraction of time that economizers in existing buildings increase VRs was needed, because we assume these scenarios have no impact on VRs when economizers are activated. For analyses of scenario 4, we required information on the VRs in office buildings when economizers are activated in order to apply equations 1 - 4 . We employed a widely used building energy simulation program (EnergyPlus) and modeled prototype small, medium, and large office buildings with and without economizers. Ventilation rates sometimes increased above the minimum rate in buildings with economizers, and the VR was fixed at the minimum rate in buildings without economizers. The "enthalpy" economizer control option was selected because enthalpy-controlled economizers are less likely to cause indoor humidity problems in humid climates. The prototype buildings have been designed to be representative of the office building stock [11]. Modeling was performed for five representative U.S. climates (Baltimore, Chicago, Houston, Los Angeles, and Minneapolis). This modeling yielded hourly VRs in buildings of each size with and without economizers. For each climate and building size, annual geometric mean VRs were calculated for use in equations $1-4$. The EnergyPlus analyses also yielded estimates of building energy use in buildings with and without economizers. Outputs from modeling of scenario 4 were weighted to account for the variability of existing economizer installation as a function of building size and climate as determined from the national database (http://www.eia.doe.gov/emeu/cbecs/ ,May 6, 2011). These calculations indicated that, on average in the $50 \%$ of office building floor area with economizers, the economizers increase VRs above a $8 \mathrm{~L} / \mathrm{s}$ per person base rate $60 \%$ of the time; therefore, in the full stock of office buildings economizers increase VRs $30 \%$ of the time. Thus, for the full stock of office buildings, the VR changes associated with scenarios 1 through 3 were assumed to occur $70 \%$ of the time on average (100\% of the time in the $50 \%$ of buildings without economizers and $40 \%$ of the time in the $50 \%$ of buildings with economizers).

Costs reported for prior years were updated to 2008 by adjusting for the consumer price index (CPI) for medical care costs, and the general CPI for other costs. Costs of SBS symptoms were based on estimates of the associated health care costs (annual average \$182 after adjustment for inflation) [12]. The total cost decrease from a reduction in SBS symptoms equaled the number of office workers in which symptoms were prevented multiplied by the average annual SBS symptom cost, where the first term in this product equals the base-case prevalence of symptoms, multiplied by the percent reduction of symptoms, multiplied by the 
number of office workers subject to the scenario. This calculation was conservative because it did not account for the potential that multiple types of SBS symptoms may be prevented within the same worker. The value of a change in work performance of office workers was the product of the average fractional change in performance, the number of office workers who experienced a change in work performance, the employer's hourly cost for employee compensation http://www.bls.gov/news.release/archives/ecec_09102008.pdf (May 6, 2011), and 1920 hours of work per year. The office worker population, 41.3 million, was the sum of employees in a) management, business, and financial operations, and b) office and administrative support http://www.bls.gov/cps/cpsaat9.pdf (May 6, 2011). The employer's hourly cost of office work (\$38.9) was a weighted value that accounted for the number of workers in each category. The resulting weighted-average annual total cost for office work was $\$ 74,695$. The economic value of a day of absence was eight times the employer's hourly cost of work. The floor area of the office building stock consistent with the population of 41.3 million office workers, required in some cost calculations, was based on the gross floor area per occupant $\left(40.3 \mathrm{~m}^{2}\right)$ calculated from a national database [13] and on the office worker population of 41.3 million. The resulting floor area was $1.66 \times 10^{9} \mathrm{~m}^{2}$.

The primary analyses of the energy cost of changing VRs in scenarios 1through 3 were based on simulations [1, 14] showing that building energy consumption varied approximately linearly with VR, with other factors constant. From the data provided from simulations of building energy use with and without mechanical ventilation, plus a floor area per office worker of $40.3 \mathrm{~m}^{2}$ [15], the office-sector annual changes in gas and electricity use were estimated to equal 0.346 and $0.008 \mathrm{kWh}$ per square meter of floor area, respectively, for each $1 \mathrm{~L} / \mathrm{s}$ per person change in VR. The cost of changing VRs in scenarios 1 through 3 reflected these unit costs, the magnitude of the changes in VR, the office floor area, and the 2008 U.S. average prices of gas (\$0.043 per $\mathrm{kWh}$ ) http://tonto.eia.doe.gov/dnav/ng/hist/n3020us3m.htm (May 6, 2011) and electricity (\$0.104 per kWh) http://www.eia.doe.gov/cneaf/electricity/epm/table5_3.html (May 6, 2011) for commercial customers.

Because implementation costs for scenarios 1 through 3 were expected to be small relative to benefits, implementation costs were only estimated for scenario 4, the addition of economizers, and the estimate is very approximate. We obtained unpublished estimates of the initial costs of economizer systems that were used in the development of a national building energy standard [16]. The cost varied from $\$ 219$ per $\mathrm{kW}$ of cooling capacity for a very small $10.5 \mathrm{~kW}$ air conditioning system (within the size range of residential systems) to $\$ 25$ per $\mathrm{kW}$ for a larger $105 \mathrm{~kW}$ system. We assumed that economizers would be added primarily to air conditioning systems with a cooling capacity of 26 to $52 \mathrm{~kW}$, for which the estimated economizer cost ranges from $\$ 88$ to $\$ 55$ per $\mathrm{kW}$. With a typical $54 \mathrm{~L} / \mathrm{s}$ of supply air flow rate per $\mathrm{kW}$ of cooling capacity and an average $5.8 \mathrm{~L} / \mathrm{s}$ design supply flow rate per square meter of floor area [15], one can estimate the cost of providing economizers as $\$ 6$ to $\$ 9$ per square meter of floor area. Based on service life data for comparable building equipment, we assumed a 15-year system life and consequently divided these initial costs by 15 to produce rough estimates of annualized costs. For scenario 4, these annual costs were multiplied by the floor area served by the added economizer systems, which is $50 \%$ of the total U.S. office floor space [13]. Not included in this calculation is an estimate of the cost of maintenance needed to keep economizer systems operating properly. 


\subsection{RESULTS}

Table 1 provides the estimated benefits and costs. Unless otherwise noted all benefits are averages or totals for the full office worker population of 41.3 million. For scenario 1 , the estimated annual benefits are a $0.33 \%$ average increase in work performance, prevention of SBS symptoms in 0.5 million workers, and prevention of 9.4 million days of short-term absence with a total economic benefit of $\$ 13.0$ billion, which compares to the estimated annual energy cost of $\$ 0.05$ billion. The estimated annual benefits of scenario 2 are a $0.91 \%$ average increase in work performance, prevention of SBS symptoms in 1.4 million workers, and prevention of 30 million days of short-term absence with a total benefit of $\$ 37.5$ billion, which compares to the estimated annual energy cost of $\$ 0.19$ billion. The decrease in minimum VR in scenario 3 is projected to save $\$ 0.04$ billion in energy costs annually, but with a net annual cost of $\$ 12.1$ billion. Adding economizers where lacking (scenario 4), is projected to increase work performance by $1.6 \%$ in 20.7 million workers, prevent SBS symptoms in 1.2 million workers, and prevent 28 million days of short term absence with a total annual economic benefit of $\$ 32.9$ billion. In addition, scenario 4 saves an estimated $\$ 0.32$ billion in energy costs each year. The estimated annualized economizer installation cost for scenario 3 is $\$ 0.42$ billion. One cannot add the results of the different scenarios because of substantial overlaps in how the scenarios affect VRs.

Table 1. Estimated annual benefits and costs of the scenarios.

\begin{tabular}{|c|c|c|}
\hline Scenario & Benefits and Costs $\wedge$ & $\begin{array}{l}\text { Economic Benefits } \\
\quad(\$ \text { billion })^{\wedge}\end{array}$ \\
\hline 1) increase & Average $0.33 \%$ increase in performance & $\$ 10.1$ \\
\hline minimum & Average $5.2 \%$ decrease in weekly SBS symptoms* & $\$ 0.09$ \\
\hline VR from 8 to & 9.4 million days of short-term absence prevented & $\$ 2.9$ \\
\hline $10 \mathrm{~L} / \mathrm{s}$ per & Increased energy consumption & $-\$ 0.05$ \\
\hline person & Total economic benefit & $\$ 13.0$ \\
\hline 2) increase & Average $0.91 \%$ increase in performance & $\$ 28.0$ \\
\hline minimum & Average $15 \%$ decrease in weekly SBS symptoms ${ }^{*}$ & $\$ 0.26$ \\
\hline VR from 8 to & 30 million days of short-term absence prevented & $\$ 9.4$ \\
\hline $15 \mathrm{~L} / \mathrm{s}$ per & Increased energy consumption & $-\$ 0.19$ \\
\hline person & Total economic benefit & $\$ 37.5$ \\
\hline 3) decrease & Average $0.32 \%$ decrease in performance & $-\$ 9.8$ \\
\hline minimum & Average $4.5 \%$ increase in weekly SBS symptoms ${ }^{*}$ & $-\$ 0.08$ \\
\hline VR from 8 to & 7.5 million added days of short-term absence & $-\$ 2.3$ \\
\hline $6.5 \mathrm{~L} / \mathrm{s}$ per & Decreased energy consumption & $\$ 0.04$ \\
\hline person & Total economic benefit & $-\$ 12.1$ \\
\hline $\begin{array}{l}\text { 4) with } \\
\text { minimum }\end{array}$ & $\begin{array}{l}\text { Average } 1.6 \% \text { increase in performance for } 20.7 \text { million } \\
\text { workers }\end{array}$ & $\$ 24.2$ \\
\hline $\begin{array}{l}\text { VR of } 8 \mathrm{~L} / \mathrm{s} \\
\text { per person }\end{array}$ & $\begin{array}{l}\text { Average } 25 \% \text { decrease in weekly SBS symptoms in } 20.7 \\
\text { million workers }\end{array}$ & $\$ 0.22$ \\
\hline add & 28 million days of short-term absence prevented & $\$ 8.6$ \\
\hline economizers & Energy savings & $\$ 0.32$ \\
\hline \multirow[t]{2}{*}{ when absent } & Annualized economizer installation cost & $-\$ 0.42$ \\
\hline & Total economic benefit & $\$ 32.9$ \\
\hline
\end{tabular}

*symptoms prevented in 0.5, 1.4, -0.4, and 1.2 million workers for scenarios 1, 2, 3, and 4, respectively $\wedge$ benefits in italics have higher uncertainty as they depend on results of a single study

\subsection{DISCUSSION}

The estimated benefits of increasing VRs in U.S. offices are modest at the level of individuals but very substantial for the full office work force. Depending on the scenario, the total net estimated economic benefit ranges from $\$ 13$ billion to $\$ 38$ billion. The estimated benefits of 
scenarios 1 and 2 far exceed the energy costs of these scenarios, while scenario 4 saves energy. The estimated costs of a small decrease in minimum VR in scenario 3 far outweigh the savings from reduced energy consumption.

Although we are unable to quantitatively estimate the uncertainties in the magnitudes of the projected health and economic benefits, we believe that the uncertainties are large, perhaps a factor of two or three. Our approximate understanding of how VR affects health, performance, and absence is the main source of uncertainty. The costs of SBS symptoms are also uncertain. The documentation supporting the unit costs for SBS symptoms is sketchy [12] and the unit costs account only for health care (no economic value was assigned to quality of life improvement when symptoms are prevented). However, given that the estimated economic impacts from changes in SBS symptoms are small relative to other projected economic changes, this source of uncertainty has a small impact on our overall estimates. We note that SBS symptoms sometimes lead to lawsuits and expensive investigations and the benefits of avoiding these lawsuits and investigations are not included in our analyses. Also, there is some evidence that SBS symptoms reduce work performance $[17,18]$, another factor not considered in this paper but important to address in future research.

The estimates of the energy cost of increased ventilation, derived from the model predictions $[1,14]$ also have a significant uncertainty. To check these estimates, we calculated energy costs using results of our in-house modelling with the EnergyPlus program of prototypical small, medium, and large office buildings located in five climates with VRs of 8 and $13 \mathrm{~L} / \mathrm{s}$ per person. The resulting predicted increases in energy cost per unit increase in VR were approximately $50 \%$ higher than the values derived in the primary energy analyses. While the estimates based on Griffith and Benne and colleagues are expected to be more accurate since they better account for the diversity of buildings and climates, the comparison suggests significant uncertainty in the energy costs. Despite this uncertainty the energy costs or savings remain small relative to the projected benefits or costs associated with performance, symptoms, and absence.

The estimates of costs, and of possible benefits, are incomplete. Equipment and installation costs were only estimated for scenario 4 - addition of economizers. Only one estimate was identified for the cost of maintenance needed to keep economizers operating properly [19] and the estimate is for economizers applied to small roof top air handlers with a cooling capacity of $14.6 \mathrm{~kW}$. Given the lack of estimates for larger air handlers, we applied this estimate to the $50 \%$ of office building stock in which economizers are added. This study reported a $48 \%$ rate of economizer failure over 15 years, an estimated repair cost of \$377 per air handler over the 15-year period, and a supply air flow rate of $0.040 \mathrm{~m}^{3} / \mathrm{s}$ per kilowatt of cooling capacity. Combining these data with a typical supply air flow rate of $5.86 \mathrm{~L} / \mathrm{s}$ per square meter of floor area [15], the estimated annual economizer maintenance cost is $\$ 0.25$ per square meter of floor area. For the $8.3 \times 10^{8} \mathrm{~m}^{2}$ floor area in which economizers are added, the annual maintenance cost is estimated to equal $\$ 0.2$ billion per year. This rough estimate of the annual maintenance cost for scenario 4 is small relative to the estimated annual benefit of $\$ 33$ billion. Incidentally, a similar maintenance expenditure may be needed to maintain proper functioning of the existing economizer systems in office buildings.

The implementation costs for scenarios 1 through 3 are likely to be small. In most buildings, only adjustment of damper settings will be necessary to change VRs. In some buildings, the capacity of heating and cooling equipment may be insufficient to accommodate the increased heating and cooling loads during periods of severe cold or hot weather. 
For scenarios 1 and 2, improvements in symptoms, performance and absence come at the cost of increased energy consumption, although the increases in energy costs are small relative to the projected benefits. However, scenario 4 saves energy while also yielding benefits nearly as large as scenario 2. Given the expected adverse consequences of energy use on carbon dioxide emissions and climate change, preference should be given to implementing scenarios that save energy.

No prior estimates were identified of the same or very similar scenarios. Mendell [18] estimated annual potential savings of $\$ 4$ to $\$ 70$ billion from measures that reduced SBS symptoms in U.S. workers, but their estimates assumed that reduced SBS symptoms led to improved work performance while the current analysis considers only the health care costs for SBS symptoms. Mendell [18] also estimated \$3 to \$4 billion in annual savings due to reductions in communicable respiratory illnesses in U.S. workers. Fisk [20] used the same basic approach as this paper to estimate the benefits of increasing VRs, but for a different set of scenarios in which the starting point was an estimate of the distribution of existing VRs in the office buildings stock. The projected benefits were similar in magnitude to those presented in this paper, but smaller because many existing office buildings already have VRs above the $8 \mathrm{~L} / \mathrm{s}$ per person base case value assumed in this paper.

All of the referenced studies underlying the relationships for VRs with performance, absence, and SBS symptoms analyzed VRs on a L/s per person basis, and were performed before the currently industry ventilation standard adopted a two component approach for determining minimum VRs based on the number of occupants and floor area [9]. In a sense, these older VRs intrinsically incorporate both the occupant and building related components of the current ventilation standard. Thus, the VR increases associated with scenarios 1 and 2 would reflect increases to both the occupant and building related components in the current ventilation standard. It is not known, however, based on the data available, whether the same (or different) percentage increases should be applied to the occupant and building related components in the standard to achieve the potential benefits described in this paper.

This paper projects overall benefits and costs for the building stock. It is important to recognize that the estimated benefits and costs of the scenarios are not applicable to every individual building in which the scenario is implemented. In some climates and building sizes, for example, the benefits of adding economizers may not exceed installation and maintenance costs.

\subsection{CONCLUSIONS}

Based on the weight of available evidence, and despite the underlying uncertainties, the benefits of increasing VRs in offices above the minimum requirements in standards are substantial in magnitude and far exceed the energy costs. More widespread use of economizers to increase VRs is projected to result in similar magnitude benefits while also saving energy.

\subsection{ACKNOWLEDGEMENT}

This study was funded through interagency agreement DW-89-92224401 between the Indoor Environments Division, Office of Radiation and Indoor Air of the U.S. Environmental Protection Agency (EPA) and the U. S. Department of Energy under contract DE-AC0205CH11231, to develop an IAQ Scientific Findings Resource Bank (see www.iaqscience.lbl.gov). Conclusions in this paper are those of the authors and not 
necessarily those of the U.S. EPA. The authors thank Spencer Dutton and Rengie Chan for reviewing a draft of a document on which this paper was based, Woody Delp for analyses of economizer installation in the existing building stock, and Michael Spears for checking calculations.

\subsection{REFERENCES}

[1] Benne K, Griffith B, Long N, Torcellini P, Crawley D, Logee T. Assessment of the energy impacts of outside air in the commercial sector, NREL/TP-550-41955. Golden, CO: National Renewable Energy Laboratory; 2009.

[2] Seppänen OA, Fisk WJ, Mendell MJ. Association of ventilation rates and $\mathrm{CO}_{2}$ concentrations with health and other responses in commercial and institutional buildings. Indoor Air. 1999;9:226-52.

[3] Seppänen O, Fisk WJ, Lei QH. Ventilation and performance in office work. Indoor Air. 2006;16:28-36.

[4] Fisk WJ, Mirer AG, Mendell MJ. Quantitative relationship of sick building syndrome symptoms with ventilation rates. Indoor Air. 2009;19:159-65.

[5] Milton DK, Glencross PM, Walters MD. Risk of sick leave associated with outdoor air supply rate, humidification, and occupant complaints. Indoor Air. 2000;10:212-21.

[6] Shendell DG, Prill R, Fisk WJ, Apte MG, Blake D, Faulkner D. Associations between classroom $\mathrm{CO}_{2}$ concentrations and student attendance in Washington and Idaho. Indoor Air. 2004;14:333-41.

[7] Li Y, Leung GM, Tang JW, Yang X, Chao CY, Lin JZ, et al. Role of ventilation in airborne transmission of infectious agents in the built environment - a multidisciplinary systematic review. Indoor Air. 2007;17:2-18.

[8] Janssen JE. Working with ANSI/ASHRAE Standard 62-1989. ASHRAE Journal. 1992;34:23-5.

[9] ASHRAE. ANSI/ASHRAE Standard 62.1-2010. Ventilation for acceptable indoor air quality. Atlanta, GA: American Society of Heating, Refrigerating, and Air Conditioning Engineers, Inc.; 2010.

[10] Brightman HS, Milton DK, Wypij D, Burge HA, Spengler JD. Evaluating buildingrelated symptoms using the US EPA BASE study results. Indoor Air. 2008;18:335-45.

[11] Deru M, Field K, Studer D, Benne K, Griffith B, Torcellini P, et al. U.S. Department of Energy reference building models of the national building stock, NREL/TP 5500-46861. Boulder, CO: National Renewable Energy Laboratory; 2011.

[12] EPA. The EPA cost of illness handbook. Washington, D.C.: U.S. Environmental Protection Agency; 2007.

[13] U.S. Energy Information Administration. 2003 Commercial building energy consumption survey. Washington, D. C. 2003.

[14] Griffith B, Long N, Torcellini P, Judkoff R, Crawley D, Ryan J. Methodology for modeling building energy performance across the commercial sector. National Renewable Energy Laboratory, NREL/TP-550-41956; 2008.

[15] Persily AK, Gorfain J. Analysis of ventilation data from the U.S. Environmental Protection Agency Building Assessment Survey and Evaluation (BASE) Study, NISTIR7145-Revised. Bethesda. MD: National Institute for Standards and Technology; 2008.

[16] ANSI/ASHRAE. ANSI/ASHRAE Standard 90.1 Energy standard for buildings except low rise residential buildings. Atlanta, GA: American Standard of Heating, Refrigerating, and Air Conditioning Engineers, Inc.; 2007.

[17] Fisk WJ. Health and productivity gains from better indoor environments and their relationship with building energy efficiency. Annual Review of Energy and the Environment. 2000;25:537-66. 
[18] Mendell MJ, Fisk WJ, Kreiss K, Levin H, Alexander D, Cain WS, et al. Improving the health of workers in indoor environments: priority research needs for a national occupational research agenda. American Journal of Public Health. 2002;92:1430-40.

[19] California Utilities Statewide Codes and Standards Team. Draft measure information template - light

commercial unitary HVAC, 2013 California building energy efficiency standards, http://www.h-m-

g.com/T24/NonresHVAC/2013_CASE_HVAC\%20Controls\%20and\%20Economizing_03302 011.pdf. 2011.

[20] Fisk WJ, Black D, Brunner G. Benefits and costs of improved IEQ in offices. Indoor Air. 2011;doi:10.1111/j.1600-0668.2011.00719.x. 